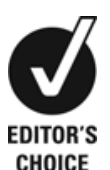

CHOICE

\title{
Sturge-Weber syndrome: oral and extra-oral manifestations
}

\author{
Amitandra Kumar Tripathi, ${ }_{1}^{1}$ Vivek Kumar, ${ }^{2}$ Rahul Dwivedi, ${ }_{1}^{3}$ Charanjit Singh Saimbi ${ }^{4}$
}

${ }^{1}$ Department of

Periodontology, Career

Postgraduate Institute of

Dental Sciences and Hospital,

Lucknow, Uttar Pradesh, India

${ }^{2}$ Department of

Periodontology, Career

Postgraduate Institute of

Dental Sciences and Hospital, Lucknow, Uttar Pradesh, India

${ }^{3}$ Department of Pedodontics,

Career Postgraduate Institute

of Dental Sciences and

Hospital, Lucknow, Uttar

Pradesh, India

${ }^{4}$ Department of

Periodontology, King George's

Medical University, Lucknow,

Uttar Pradesh, India

\section{Correspondence to}

Professor Charanjit Singh

Saimbi, cssaimbi@gmail.com

Accepted 19 February 2015

CrossMark

To cite: Tripathi AK, Kumar V, Dwivedi R, et al. BMJ Case Rep Published online: [please include Day Month Year] doi:10.1136/ bcr-2014-207663

\section{SUMMARY}

Sturge-Weber syndrome is a rare, congenital, neuro-oculo-cutaneous disorder which is characterised extra-orally by unilateral port wine stains on the face, glaucoma, seizures and mental retardation, and intra-orally by ipsilateral gingival haemangioma which frequently affects the maxilla or mandible. In the present case, a 15-year-old female patient presented with a port wine stain on the right side of the face and glaucoma of the right eye, and intra-orally with gingival haemangioma on the right side of the maxilla.

\section{BACKGROUND}

Sturge-Weber syndrome (SWS) or encephalotrigeminal angiomatosis belongs to a group of disorders known as phakomatoses. In SWS, abnormal development of the primordial vascular bed occurs during the early stages of cerebral vascularisation, when the blood supply to the brain, meninges and face is undergoing reorganisation. As a result of these abnormal changes, the overlying leptomeninges are richly vascularised and the brain beneath becomes atrophic and calcified, mainly in the molecular layer of the cortex.

The main characteristic features of this disorder are port wine stains on the forehead and/or scalp, seizures and mental retardation due to angioma formation in the brain, and glaucoma. ${ }^{1}$

Schirmer provided the first detailed description of SWS in 1860, Sturge further described SWS-related dermatological, ophthalmic and neurological manifestations in 1879, and Weber reported radiological alterations seen in these patients in $1929 .^{2}$ This disorder occurs in 1:50 000 live births. ${ }^{3}$

Oral manifestations include unilateral haemangiomatous lesions in the maxillary or mandibular gingiva, lips, tongue, palatine region, etc. In gingiva, these lesion present as unilateral hyperplasia due to an increase vascular component, and demonstrate bleeding following minimal trauma. ${ }^{1}$

\section{CASE PRESENTATION}

A 15 -year-old female patient presented to the periodontology department with a 3-4-month history of pain and bleeding from the gums while eating. The patient's past medical history revealed that she had developed a convulsive disorder at the age of 1 year for which she was taking medication.

Extra-oral examination showed a port wine stain on the right side of the face (figure 1), while eye examination showed dilated blood vessels in the right eye (figure 2). Intra-oral examination showed

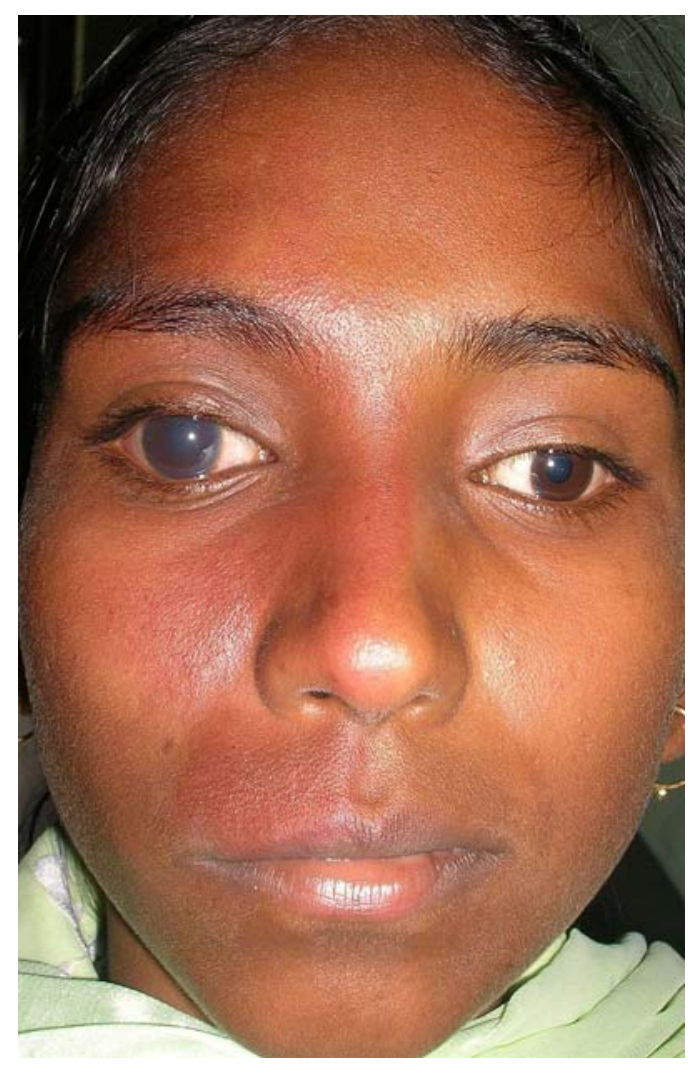

Figure 1 Port wine stain on the right side of the face.

unilateral hyperplastic lesions on the right side of the maxilla (figure 3A, B). These lesions showed blanching when pressure was applied (figure 4). The patient had poor oral hygiene.

On radiographic examination, a lateral cephalogram and postero-anterior view showed tram-line calcification (figures 5 and 6). CT showed severe alveolar bone loss on the affected side of the oral cavity (figure 7). Blood investigations were normal. Based on the history, and on clinical and radiological findings, a diagnosis of SWS was made.

The patient was treated with oral prophylaxis, advised to use a chlorhexidine mouth rinse and

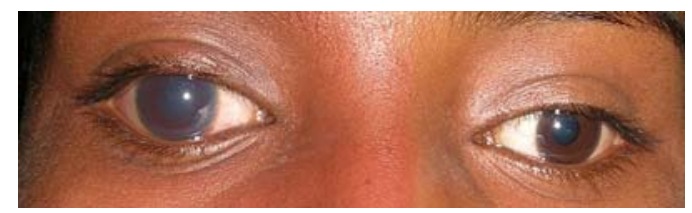

Figure 2 Dilated blood vessels in the right eye. 


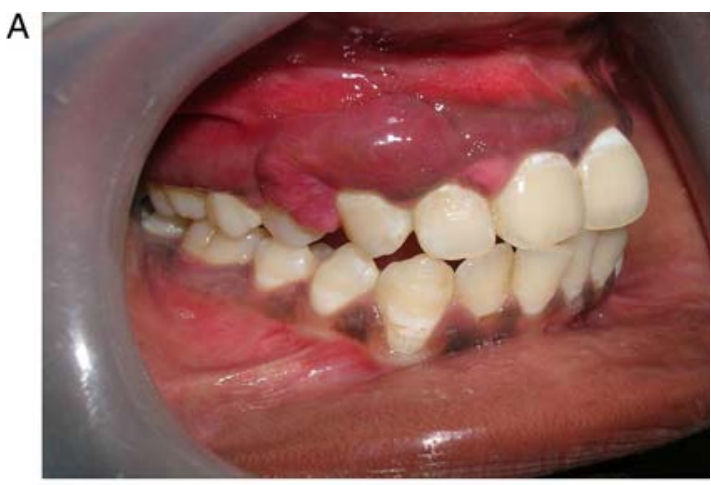

B

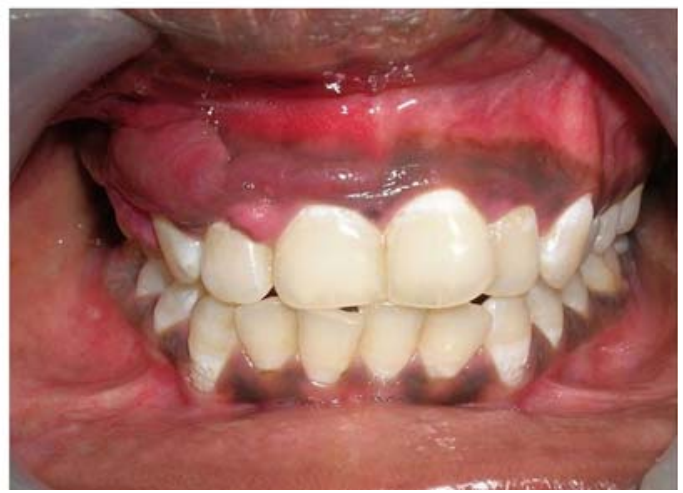

Figure 3 (A, B) Unilateral hyperplastic lesions on the right side of the maxilla.

given oral hygiene instructions. The patient and her parents were referred for psychological counselling.

\section{INVESTIGATIONS}

On radiographic examination, a lateral cephalogram and postero-anterior view showed tram-line calcification. CT showed severe alveolar bone loss on the affected side of the oral cavity. Blood investigations were normal.

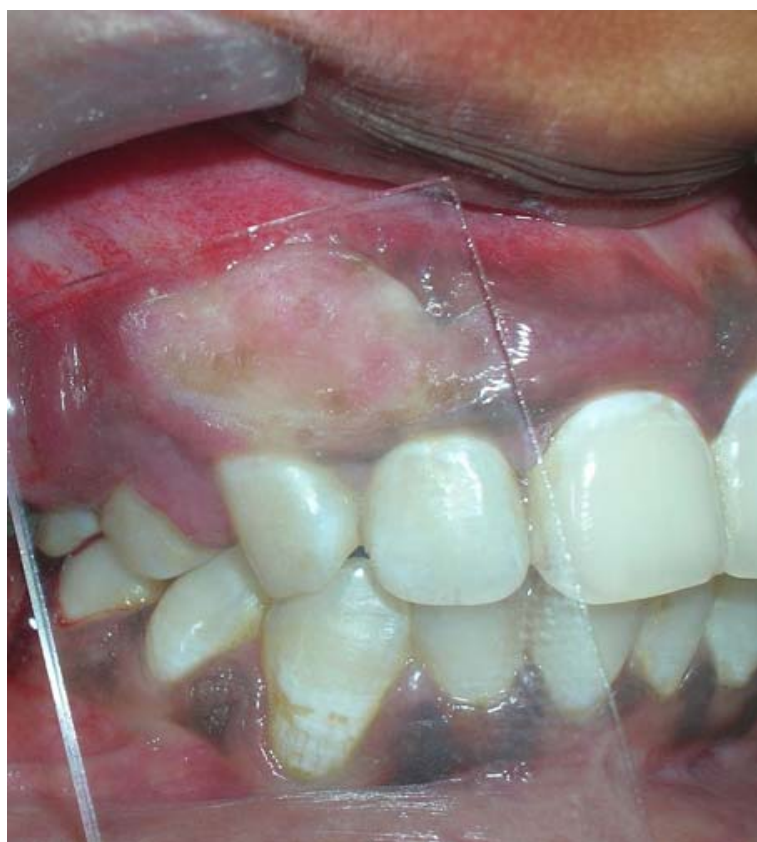

Figure 4 Blanching of lesion under pressure.

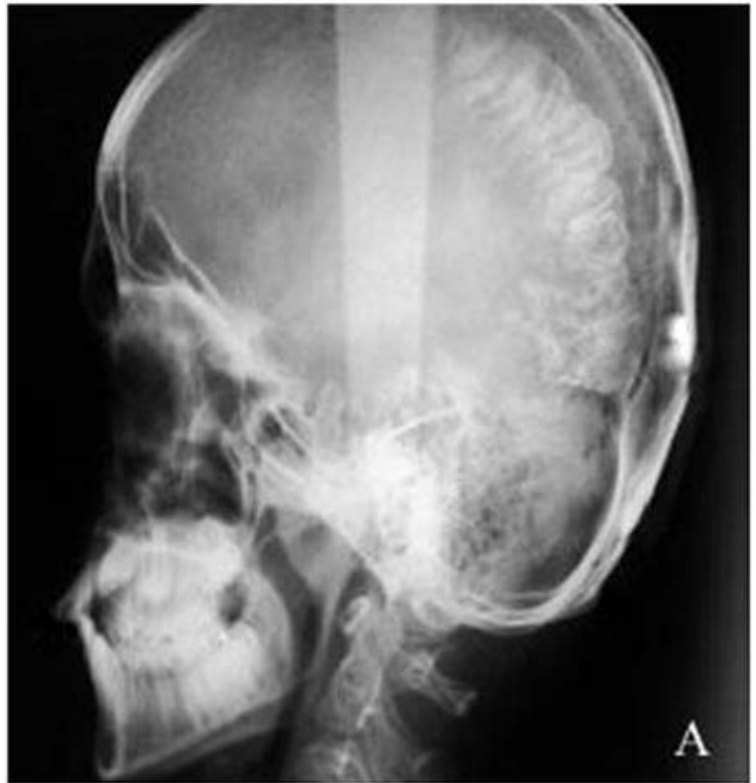

Figure 5 Lateral cephalogram showing tram-line calcification in the occipital region.

\section{DIFFERENTIAL DIAGNOSIS}

The differential diagnosis included Rendu-Osler-Weber syndrome, angio-osteodystrophy syndrome, Maffucci syndrome and Klippel-Trenaunay-Weber syndrome.

\section{TREATMENT}

Treatment consisted of establishing an oral plaque control regimen for the patient. Oral prophylaxis (scaling and root planing) was carried out and the patient was instructed on oral hygiene and the use of chlorhexidine mouth rinse. The patient and her parents were referred for psychological counselling.

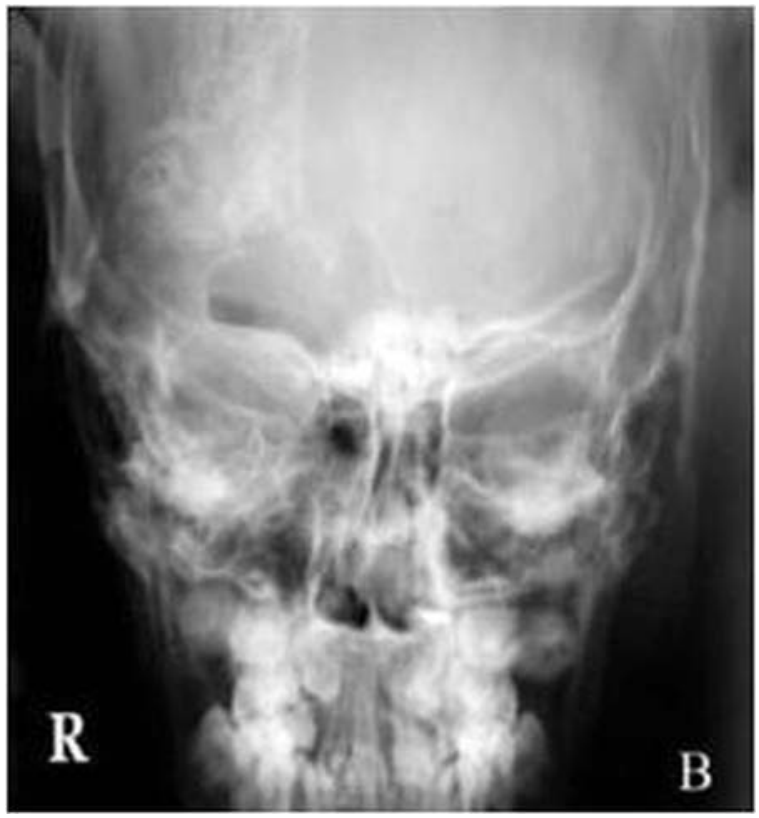

Figure 6 Postero-anterior view showing tram-line calcification in the parietal region. 


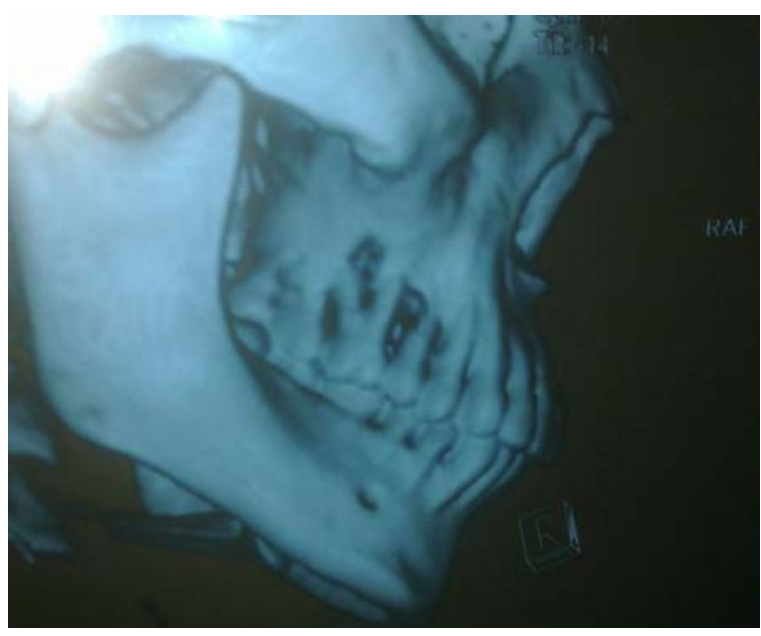

Figure 7 CT showing severe alveolar bone loss on the affected side of the oral cavity.

\section{OUTCOME AND FOLLOW-UP}

At the 1-month and 3-month follow-up visits, there was a significant improvement in the patient's chief complaint and maintenance of oral hygiene was noted.

\section{DISCUSSION}

SWS consists of a group of disorders which may present with neurological, cutaneous, ocular and oral manifestations. The most common clinical characteristic is a port wine stain on the face which normally follows the course of the trigeminal nerve, especially the ophthalmic division. ${ }^{4}$ Port wine stains are reported in about $87-90 \%$ of cases and generally occur on the right side, although these lesions present bilaterally in about $33 \%$ of cases. ${ }^{5}$ In the present case, the port wine stain was present on the right side of the face.

Leptomeningeal angiomatosis is another important clinical feature of this syndrome, and can lead to contra-lateral hypertrophy, progressive cerebral calcification, epileptic convulsions and mental retardation. ${ }^{4}$ In this case, the patient had a history of epileptic convulsions and her skull radiograph showed intracranial calcification in the occipito-parietal region.

According to the Roach scale, SWS is classified as follows: ${ }^{6}$

Type I: both facial and leptomeningeal angiomas; may have glaucoma

Type II: facial angiomas only (no CNS involvement); may have glaucoma
Type III: isolated leptomeningeal angioma; usually no glaucoma.

According to the above criteria, our case was type I SWS as the patient had a port wine stain and glaucoma on the right side with epileptic convulsions and calcification of the occipitoparietal region.

The most common oral manifestations in SWS are mainly seen in the unilateral side of the gingiva and finish abruptly at the midline. Angiomatous gingival lesions range from slight vascular hyperplasia to severe haemangiomatous proliferation due to abnormal increases in the vascular component. As a result of these changes, gingiva bleed on slight provocation or minor trauma. ${ }^{2}$

In the present case, massive haemangiomatous proliferation was seen on the right side of the maxillary gingiva which blanched on the application of pressure and bled profusely following slight trauma.

\section{Learning points}

- Sturge-Weber syndrome presents with a large number of clinical manifestations and early diagnosis is difficult.

- Early diagnosis is necessary to allow future complications, mainly CNS related, to be controlled.

- Expert psychological counselling of patients and their parents is necessary.

\section{Competing interests None.}

Patient consent Obtained.

Provenance and peer review Not commissioned; externally peer reviewed.

\section{REFERENCES}

1 Royle HE, Lapp R, Ferrara ED. The Sturge-Weber syndrome. Oral Surg Oral Med Oral Pathol 1966;22:490-7.

2 Neto FXP, Junior MAV, Ximenes LS, et al. Clinical features of Sturge-Weber syndrome. Intl Arch Otorhinolaryngol 2008;12:565-70.

3 Welty LD. Sturge-Weber syndrome: a case study. Neonatal Netw 2006;25:89-98.

4 Mukhopadhyay S. Sturge-Weber syndrome: a case report. J Indian Soc Pedod Prev Dent 2008:26:29-30.

5 Inan CJM. Sturge-Weber syndrome; report of an unusual cutaneous distribution. Brain Develop 1999;21:68-70.

6 Del Monte M, Eisbschitz-Tsimhoni M. Sturge-Weber syndrome: overview. eMedicine February, 2007. 